\title{
PEMBELAJARAN BAHASA MANDARIN ANAK USIA DINI DI YAYASAN PENDIDIKAN ISLAM AR-RAHMAH
}

\section{THE LEARNING OF MANDARIN TO EARLY CHILDHOOD AT AR-RAHMAH ISLAMIC EDUCATION SCHOOL}

\author{
Niza Ayuningtias $^{1 *}$, Mhd. Pujiono ${ }^{2)}$, Vivi Adryani Nasution ${ }^{3)}$, Ely Hayati Nasution ${ }^{4)}$ \\ ${ }^{1)}$ Fakultas Ilmu Budaya, Universitas Sumatera Utara, email: niza@usu.ac.id \\ ${ }^{2)}$ Fakultas Ilmu Budaya, Universitas Sumatera Utara, email: mhd.pujiono@usu.ac.id \\ ${ }^{3)}$ Fakultas Ilmu Budaya, Universitas Sumatera Utara, email: vivi.adryani@usu.ac.id \\ ${ }^{4)}$ Fakultas Ilmu Budaya, Universitas Sumatera Utara, email: ely.hayati@usu.ac.id
}

\begin{abstract}
ABSTRAK
Bahasa Mandarin telah dijadikan sebagai salah satu mata pelajaran di sekolah-sekolah yang ada di Indonesia termasuk TK/PAUD.Namun demikian, banyak kendala yang dihadapi oleh pihak sekolah. Minimnya pelatihan dan tenaga pendidik bahasa Mandarin untuk pendidikan anak usia dini menggerakkan hatiTim Pengabdian Kepada Masyarakat USU untuk mengadakan pelatihan Pembelajaran Bahasa Mandarin Anak Usia Dini kepada tenaga pendidik pra-sekolah di salah satu sekolah Taman Kanak-Kanak yang ada di kota Medan yaitu RA Ar-Rahmah. Metode pelaksaan kegiatan ini adalah pelatihan intensif dengan perpaduan teori dan praktek serta diskusi dan unjuk kerja dari hasil pelatihan. Pengajaran bahasa Mandarin kepada para tenaga pendidik dilakukan dengan prinsip "Pengajaran bahasa Mandarin terhadap anak usia dini" dengan tetap mempertimbangkan dan menghormati posisi peserta sebagai pengajar yang memiliki latar belakang dan pengalaman yang berbeda-beda. Pelatihan mengikut prinsip TCFL (Teaching Chinese as $A$ Foreign Language)berupa materi yang aplikatif dan sederhana melaluiflashcard, kertas lipat, menyanyi lagu-lagu sederhana, cara memperkenalkan diri, dan lain-lain. Hasil praktek pengajaran yang dilakukan sangat memuaskan dan sesuai dengan yang diharapkan.
\end{abstract}

Kata kunci: Bahasa Mandarin, Anak-usia-dini, TCFL

\section{ABSTRACT}

Mandarin has been used as one of the subjects in Indonesia's schools including kindergarten/PAUD. However, many obstacles faced by the school. The lack of training and teaching staff of Mandarin for early childhood education moved the hearts of the USU Community Service Team to conduct Early Childhood Mandarin Learning training for pre-school educators in one of the Kindergarten schools in Medan, namely RA Ar-Rahmah. The method of this activity is intensive training with a blend of theory and practice as well as discussion and performance of the training results. Teaching Mandarin to educators is carried out with the principle of "Teaching Mandarin to young children" while still considering and respecting the position of participants as instructors who have different backgrounds and experiences.The training follows the principles of TCFL (Teaching Chinese as A Foreign Language) in the form of applicative and simple material through flashcards, folding paper, singing simple songs, how to introduce yourself, etc. The results of the teaching practice carried out were very satisfying and as expected.

Keywords: Mandarin, Early childhood, TCFL

\section{PENDAHULUAN}

Bahasa Mandarin adalah salah satu bahasa yang penting di dunia sehingga menjadi bahasa resmi yang digunakan oleh $\mathrm{PBB}$ diantara lima bahasa resmi lainnya. Bahasa Mandarin merupakan salah satu bahasa asing yang kedudukannya semakin penting di Indonesia, tidak lagi menjadi bahasa yang hanya dipelajari di sekolah-sekolah tertentu, tetapi menyebar ke hampir seluruh sekolah yang ada di 
Indonesia.Sekolah sebagai institusi pendidikan merupakan tempat proses pendidikan dilakukan, memiliki keterlibatan dalam membantu memenuhi kebutuhan masyarakat, khususnya peningkatan kompetensi guru agar dapat menyeimbangkan dengan perkembangan teknologi dan informasi yang sangat pesat. Dengan demkian, guru diharapkan mampu mengajar dan mendidik siswa dengan baik dan berkompeten. Guru yang berkompeten dan mampu mendidik siswa dengan baik menciptakan siswa yang cerdas dan berkompeten pula. Khususnya dalam mengajar bahasa Mandarin dapat dimulai dari pendidikan anak usia dini.

Anak usia dini adalah anak yang berada pada usia 0-8 tahun yang sedang dalam tahap pertumbuhan dan perkembangan, baik fisik maupun mental. Menurut Beichler dan Snowman [1], anak usia dini adalah anak yang berusia antara 3-6 tahun. Pada hakikatnya, anak usia dini adalah individu yang unik dimana ia memiliki pola pertumbuhan dan perkembangan dalam aspek fisik, kognitif, sosio-emosional, kreativitas, bahasa dan komunikasi yang khusus yang sesuai dengan tahapan yang sedang dilalui oleh anak tersebut. Masa anak usia dini sering disebut dengan istilah "golden age" atau masa emas. Pada masa ini, hampir seluruh potensi anak mengalami masa peka untuk tumbuh dan berkembang secara cepat dan hebat. Oleh karena itu, masa usia dini adalah masa "golden age" yang harus dioptimalkan mulai dari aspek kognitif, sosio-emosional, kemampuan fisik, termasuk bahasa dan lain sebagainya. Jika sejak dini, anak sudah dibekali maka ketika beranjak dewasa atau tumbuh besar. Ilmu yang didapatkan akan berdampak sampai anak dewasa.Begitu juga dengan mengajarkan bahasa Mandarin kepada anak sejak dini dapat memberikan bekal untuk mereka kelak dewasa nanti, terutama kepada anak yang bahasa ibunya bukan bahasa Mandarin.

Mengajar atau mendidik anak usia dinidi sekolah memerlukan perhatian khusus dan metode yang menyenangkan dan tetap memperhatikan psikologis anak. Seperti penelitian sebelumnya yang dilakukan oleh [2] menunjukkan bahwa metode mengajar kepada anak usia dini/TK harus menyenangkan dan aplikatif. Penelitian yang dilakukannya berupa pengajaran membaca melalui permainan flashcard. Hasil yang diperoleh menunjukkan bahwa flashcard sangat efektif untuk meningkatkan daya ingat anak terhadap kosa kata yang dipelajari sehingga kemampuan anak dalam membaca juga semakin pesat. Tampilan flashcardyang menarik, penuh warna dan menyenangkan membuat anak bersemangat dan antusias ketika belajar.Metode pembelajaran bahasa Mandarin juga demikian, seperti penelitian yang dilakukan oleh [3] mengenai pengajaran bahasa Mandarin sebagai bahasa asing kepada anak-anak Amerika. Dalam penelitian menunjukkan bahwa ada beberapa metode pengajaran bahasa Mandarin yang dapat dilakukan yaitu melalui permainan, cerita legenda/budaya, diskusi, bernyanyi, berpuisi, 
menari bersama, dan membuat kerajinan tangan sederhana.

Dewasa ini, sekolah-sekolah yang didirikan untuk pendidikan anak usia dini telah banyak berada di daerah kota Medan. Salah satunya ialah Yayasan Pendidikan Islam Ar-Rahmah yang bertempat di Jl. Eka Rasmi Gg. Pribadi Kecamatan Medan Johor Kota Medan Provinsi Sumatera Utara.Yayasan Pendidikan ArRahmah berada di lingkungan masyarakat yang mayoritasnya beragama Islam sehingga seluruh siswanya beragama Islam dan pengajaran yang diberikan kepada para siswa juga mengikut ajaran Islam.Walaupun sebagai yayasan Islam, saat ini bahasa yang dijadikan mata pelajaran tidak hanya berfokus pada bahasa Arab dan Indonesia, melainkan ada tambahan mata pelajaran bahasa lain, yakni bahasa Inggris.Pihak sekolah sempat memiliki niat untuk menambahkan bahasa Mandarin sebagai mata pelajaran tambahan untuk pengembangan diri, tetapi terhambat karena minimnya kemampuan berbahasa dan kompetensi dasar para tenaga pendidik untuk mengajarkan bahasa Mandarin kepada para siswa. Selain itu, keterbatasan dana untuk membeli sarana/prasarana penunjang pembelajaran bahasa Mandarin, seperti buku dan LCD proyektor (alat infocus) juga turut membuat pihak sekolah mengurungkan niatnya untuk menambahkan bahasa Mandarin sebagai mata pelajaran tambahan. Padahal, pembelajaran bahasa pada anak usia dini akan sangat efektif untuk menjadi bekal kedepannya. Terutama pembelajaran bahasa Mandarin mengingat bahasa Mandarin yang telah dijadikan sebagai bahasa internasional dan bahasa resmi di dunia.

Berdasarkan uraian yang telah disampaikan, pengabdian dalam bentuk pelatihan pengajaran bahasa Mandarin sangat perlu untuk dilakukan, yaitu pelatihan pengajaran bahasa Mandarin kepada seluruh tenaga pendidik Yayasan Pendidikan Islam Ar-Rahmah, yang merupakan kunci pembukaan untuk mempelajari bahasa Mandarin pada anak usia dini. Oleh karena itu, melalui kegiatan ini ditargetkan akan dapat membantu pihak mitra dalam penyediaan fasilitas, sarana, dan materi ajar yang dibutuhkan dan tentunya yang relevan dengan kegiatan pengembangan bahasa Mandarin di dalam dan di luar kelas.

Selain itu, kegiatan ini juga diharapkan dapat memberikan kontribusi positif terhadap peningkatan kualitas tenaga pendidik dari segi penambahan pengetahuan dan keterampilan praktis melaksanakan pembelajaran bahasa Mandarin terutama dalam hal penggunaan kosa kata di dalam kelas melalui penggunaan ekspresi-ekspresi sederhana yang mudah dipahami baik oleh guru maupun oleh siswa.

\section{METODE PELAKSANAAN KEGIATAN}

Sasaran dari kegiatan pengabdian masyarakat ini adalah seluruh tenaga pendidik Yayasan Pendidikan Islam Ar-Rahmah dan dibantu oleh upaya para orang tua.Metode pelaksaan kegiatan ini adalah pelatihan intensif dengan perpaduan teori dan praktek serta diskusi dan unjuk kerja dari hasil pelatihan. 
Pengajaran bahasa Mandarin kepada para tenaga pendidik dilakukan dengan prinsip "Pengajaran bahasa Mandarin terhadap anak usia dini" dengan tetap mempertimbangkan dan menghormati posisi peserta sebagai pengajar yang memiliki latar belakang dan pengalaman yang berbeda-beda. Kegiatan ini menekankan pada pelafalan konsonan, penggunaan kosakata, lagu, cerita, gambar, dan permainan untuk membantu penyelenggaraan proses pembelajaran bahasa Mandarin untuk anak usia dini.

Secara umum, langkah-langkah kegiatan PKM ini dibagi empat, yaitu :

1. Analisa masalah dan kebutuhan.

Pada tahap analisa masalah dan kebutuhan, tim pengabdian mencari data dan informasi dari tenaga pendidik melalui wawancara dan observasi. Pada tahap ini tim mengidentifikasi masalah dan mencari solusi untuk membantu mengatasi masalah dengan melakukan forum diskusi bersama.

2. Pengajuan penawaran kerja sama.

Pada tahap selanjutnya, tim mengajukan tawaran kerja sama kepada Kepala Sekolah sebagai mitra yang memerlukan pendampingan. Dari proses ini, diperoleh kesepakatan untuk melakukan pelatihan dalam rangka kemampuan bahasa Mandarin kepada para tenaga pendidik dengan memberikan materi dan panduan yang berhubungan dengan pengajaran bahasa Mandarin pada anak usia dini.

3. Pelaksanaan kegiatan.
Tahap ketiga yaitu pelaksanaan kegiatan pelatihan dengan membuat rencana kegiatan yang terbagi menjadi sesi yaitu pengenalan, penyampaian teori dasar dan strategi pengajaran bahasa Mandarin untuk anak, dilanjutkan dengan materi yang lebih aplikatif yaitu pembelajaran melalui kosakata, lagu, video, cerita dan permainan dengan menggunakan berbagai media seperti cerita bergambar, flash card, kertas lipat, dan sebagainya.

Pelatihan yang diberikan juga harus mengikuti prinsip TCFL (Teaching Chinese as A Foreign Language) yaitu prinsip atau metode pengajaran bahasa Mandarin sebagai bahasa asing atau bahasa kedua yang dipelajari oleh pelajar asing (pelajar yang bukan memakai bahasa Mandarin sebagai bahasa pertamanya). Prinsip pengajaran bahasa Mandarin untuk anak-anak luar negeri para guru hendaknya mengajarkan bahasa Mandarin mulai dari halhal sederhana yang terdapat di lingkungan sekitar siswa dengan santai tanpa pemaksaan [3], menerangkan bahwa mengajarkan bahasa kedua (bahasa asing, terkhususnya bahasa Mandarin) kepada anak-anak haruslah sesuai dengan tata bahasa dari bahasa kedua tersebut, diajarkan secara bertahap dan meningkat sesuai dengan psikologis anak, dengan mengikuti prinsip pengajaran bahasa Mandarin kepada anak-anak asing dengan cara yang santai dan memperhatikan psikologis anak dengan tujuan untuk menarik minat anak mempelajari bahasa 
Mandarin yang secara alami meningkatkan kreativitas dan keterampilan berbahasa anak.

\section{Evaluasi.}

Kegiatan ini ditutup dengan melakukan suatu proyek pembelajaran mengenai apa yang akan mereka ajarkan kepada para siswa dalam bentuk praktek mengajar. Pada tahap akhir, para guru menuliskan manfaat nyata yang mereka rasakan dan dapatkan selama pelatihan sebagai umpan balik dari kegiatan yang telah dilakukan oleh tim pengabdian.

\section{HASIL DAN PEMBAHASAN}

Dari perkenalan yang dilakukan kepada mitra terhadap bahasa Mandarin, kemudian dilanjutkan dengan penyampaian teori dasar dan strategi pengajaran bahasa Mandarin untuk anak kepada para guru Yayasan Pendidikan Islam ArRahmah mendapat sambutan yang hangat dan penuh antusias.

Strategi pengajaran bahasa Mandarin yang diperkenalkan kepada para pendidik mengikut prinsip TCFL, oleh karena itu para pendidik dilatih untuk menerapkan pembelajaran melalui metode yang ramah pada anak dan tetap memperhatikan psikologi tiap siswanya.Kemudian, para pendidik dilatih untuk memberikan materi yang aplikatif.Berikut materi yang dilatih kepada para pendidik Yayasan Pendidikan Islam Ar-Rahmah.

1. Materi pengenalan dan pelafalan konsonan bahasa Mandarin

Materi yang digunakan berupa pembagian konsonan dan cara pelafalannya. Materi ini dilatih kepada para pendidik secara bertahap dengan penjelasan lengkap.

Tabel 1. Konsonan Bahasa Mandarin

\begin{tabular}{|l|l|l|l|}
\hline \multicolumn{4}{|c|}{ KONSONAN BAHASA MANDARIN } \\
\hline b & p & m & F \\
\hline d & t & n & L \\
\hline g & k & h & \\
\hline j & q & x & \\
\hline zh & ch & sh & R \\
\hline z & c & s & \\
\hline y & w & & \\
\hline
\end{tabular}

Selain konsonan dan pelafalan, para guru juga diberikan pelatihan untuk mengajarkan materi pembelajaran nada dalam bahasa Mandarin dan pengenalan sistem pinyin.

Tabel 2.Nada dalam Bahasa Mandarin

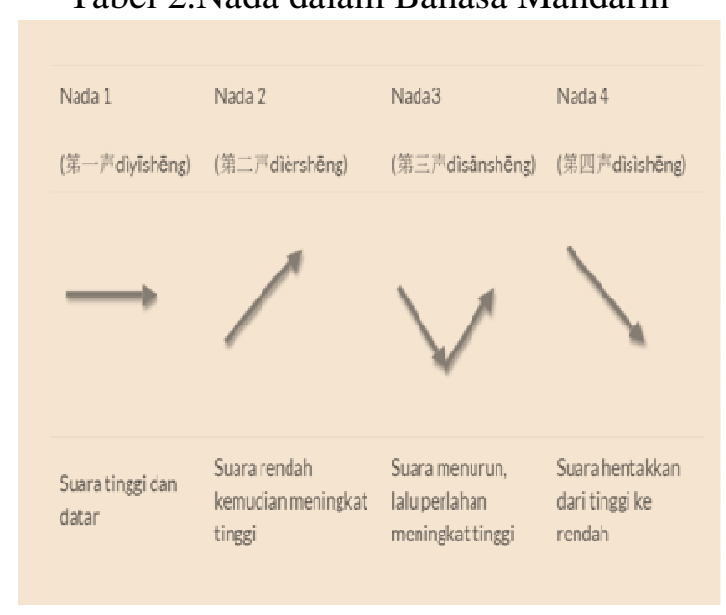

2. Materi memperkenalkan diri

Materi yang digunakan berupa cara memperkenalkan diri kepada orang lain. Para pendidik dilatih untuk mengajarkan para siswa memperkenalkan diri dalam bahasa Mandarin. Materi ini berupa aksara Mandarin, pinyin, dan pelafalannya dalam bahasa Indonesia. 
Tabel 3. Perkenalan Diri

\begin{tabular}{|c|c|}
\hline & $\begin{array}{c}\text { zìwǒjièshào } \\
\text { 自 我 介绍 } \\
\text { (Perkenalan Diri) }\end{array}$ \\
\hline & $\begin{array}{l}\text { dàjiāhăo } \\
\quad \text {;大家好, 我 叫 ........ } \\
\text { Taciahao, wo ciao............. } \\
\text { (Hallo semuanya, nama saya........) }\end{array}$ \\
\hline 2. & $\begin{array}{l}\text { jīnnián } \\
\quad \text {;今年.......(5)...... 岁 } \\
\text { Cinnien (wu) suei } \\
\text { (Tahun ini } 5 \text { tahun) }\end{array}$ \\
\hline 3. & $\begin{array}{l}\text { wǒzài yòu ér yuán } \\
\text {; 我在 ARRAHMAH 幼 U 园 } \\
\text { dúshū wǒxǐhuān zàinàbiān yīn wéi } \\
\text { 读书, 我喜 欢 在 那 边 因 为 } \\
\text { lăoshīhuìjiàowǒhěnduōběnlǐng } \\
\text { 老师 会 教 我很多 本 领。 } \\
\text { Wo cai AR RAHMAH you ar yuen tu shu, } \\
\text { wo si huan cai na bien in wei lao se huei } \\
\text { ciao wo hen tuo pen ling } \\
\text { (Saya belajar di RA AR RAHMAH, saya } \\
\text { suka belajar di sana karena guru } \\
\text { mengajarkan saya bermacam-macam } \\
\text { keterampilan) }\end{array}$ \\
\hline 4. & $\begin{array}{l}\quad \text { Xièxièdàjiā } \\
\quad \text { 谢 谢 大家! } \\
\text { Renshe nimen hen kaosing, siesie tacia } \\
\text { (Senang berkenalan dengan kalian, terima } \\
\text { kasih semuanya) }\end{array}$ \\
\hline
\end{tabular}

3. Materi pelatihan pengajaran kosakata melalui metode menyanyi lagu-lagu sederhana, salah satu diantaranya:

\section{$\underline{\text { Lagu } 2 \text { Ekor Harimau }}$}

liăng zhīlăohŭ 俩只老虎

\section{liăng zhīlăohǔ} ;两只老虎 $2 x$

Liang zhilaohu (2 ekor harimau) $2 \mathrm{x}$

$$
\begin{gathered}
\text { păo dekuài } \\
\text {; 跑得 快 } 2 \mathrm{x}
\end{gathered}
$$

Phaotekhuai (Larinyacepat) 2x

$$
\begin{gathered}
\text { yì zhīméiyǒuěrduo } \\
\text {;一只没有耳朵 }
\end{gathered}
$$

Yi zhimei you artuo( 1ekortidakpunyatelinga)

$$
\begin{gathered}
\text { yì zhīméiyǒuwěiba } \\
\text {; 一只没 有 尾巴 }
\end{gathered}
$$

Yi zhimei you wei pa ( 1ekortidakpunyabuntut)

$$
\begin{aligned}
& \text { zhēn qíguài } \\
& \text {;真奇 怪 } 2 x
\end{aligned}
$$

Zhen ci kuai (Benarbenaraneh) 2x

4. Materi pelatihan pengajaran kosa kata melalui permainan sederhana, education flash card, dan video-video pengajaran bahasa Mandarin untuk anak usia dini.

Pada bagian materi ini, para pendidik dilatih untuk mengajarkan para siswa untuk mengenal dan mengingat kosa kata sederhana melalui permainan dan flash card. Materi ini dilatih selama beberapa pertemuan pelatihan mengingat latar belakang pendidikan para pendidik tidak berasal dari bahasa Mandarin.

Berikut beberapa foto dokumentasi pada saat pelatihan.

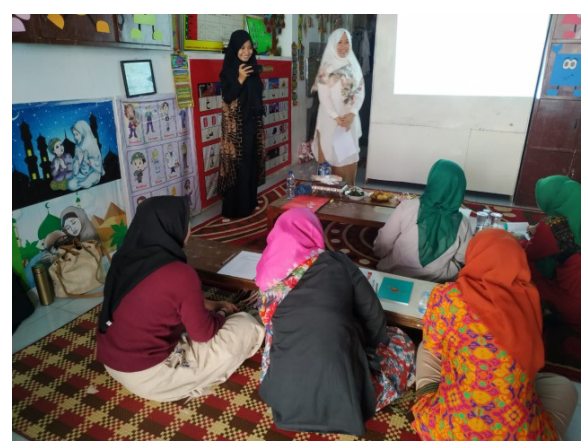

Gambar1. Suasana pelatihan dengan para pendidik Yayasan Pendidikan Islam Ar-Rahmah 


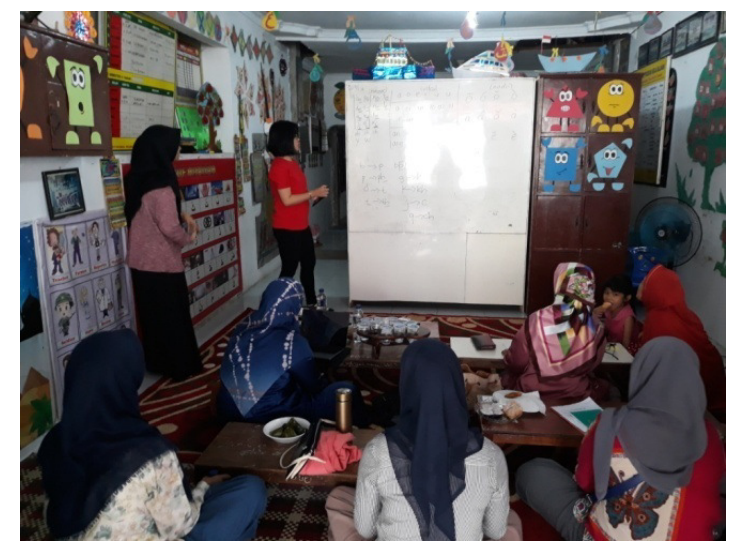

Gambar 2.Pelatihan tentang konsonan, nada dan sistem pinyin.

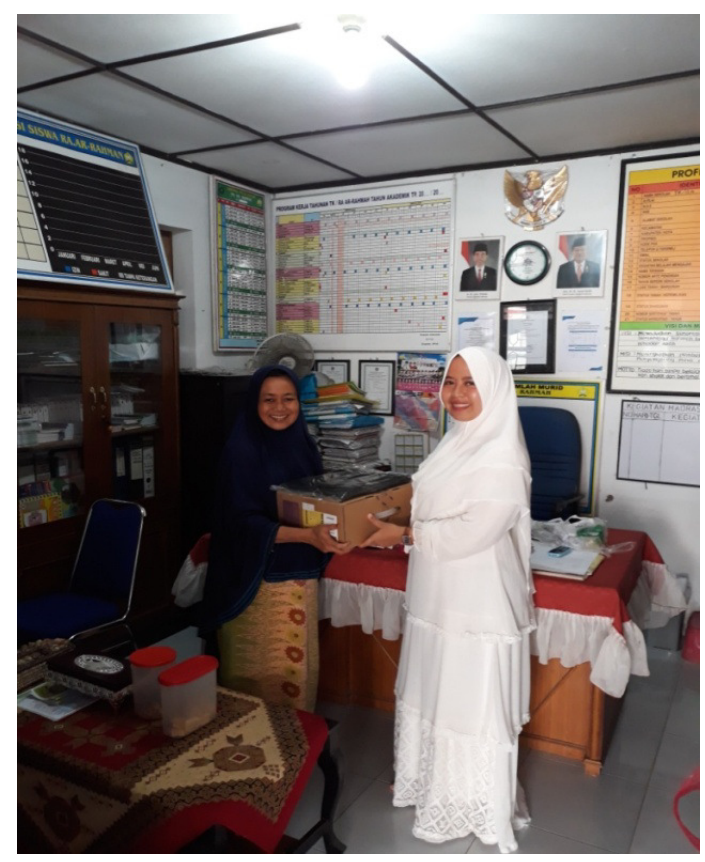

Gambar 3. Penyerahan LCD Projector dari Tim PKM USU kepada Pihak Mitra

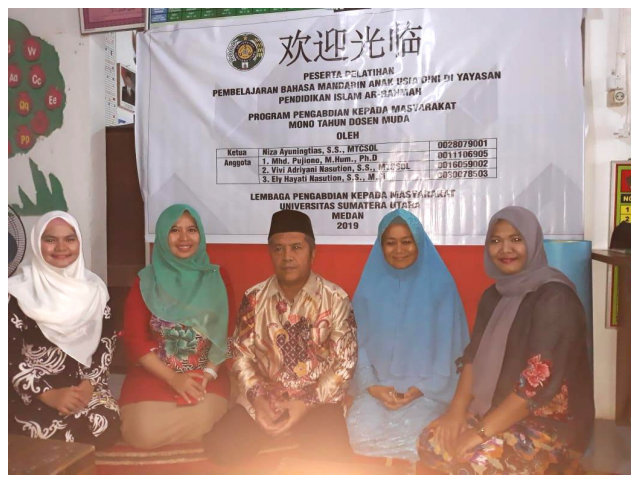

Gambar 4. Foto bersama Tim PKM USU dengan Pihak Mitra dan pengawas RA kecamatan Medan Johor

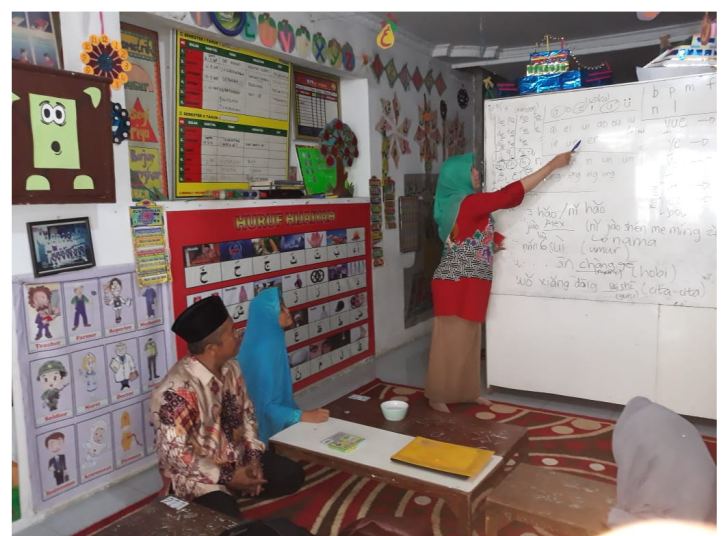

Gambar 5. Pelatihan tentang nada dan kosa kata dalam bahasa Mandarin

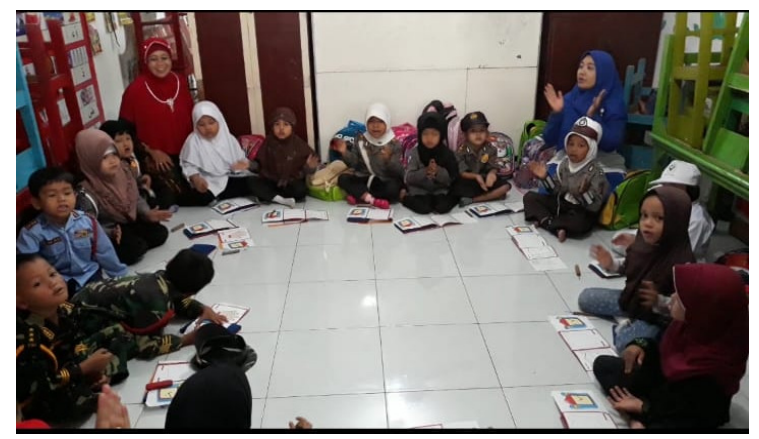

Gambar 6. Tenaga Pendidik Mempraktekkan Pembelajaran Bahasa Mandarin kepada Peserta Didik

Pelatihan dilakukan dengan baik dan intensif.Melihat keseriusan dan antusias seluruh peserta pelatihan, kegiatan yang dilakukan membuahkan hasil yang optimal dan sesuai dengan yang diharapkan.Para tenaga pendidik telah mampu menguasai materi pembelajaran bahasa Mandarin sebagaimana yang telah diberikan pada saat pelatihan.Tim PKM USU berharap pelatihan yang lebih serius dan mendalam mengenai pembelajaran bahasa Mandarin dapat dilaksanakan kembali baik di RA Ar-Rahmah maupun di sekolah-sekolah lainnya. 


\section{KESIMPULAN}

Dari hasil yang diperoleh melalui kegiatan pelatihan yang dilakukan, dapat disimpulkan bahwa:

1. Pelatihan Pembelajaran Bahasa Mandarin Anak Usia Dini di Yayasan Pendidikan Islam Ar-Rahmahmengikuti prinsip Teaching Chinese as A Foreign Language atau prinsip pengajaran bahasa Mandarin sebagai bahasa asing dengan memperhatikan psikologis tiap siswa.

2. Materi pelatihan yang diberikan kepada pihak mitra melalui prinsip Teaching Chinese as A Foreign Languageberupa materi yang aplikatif dan sederhana yang mudah dimengerti dan diingat oleh para siswa nantinya.

3. Materi pelatihan yang diberikan kepada pihak mitra berupa pembelajaran konsonan, pinyin, nada dalam bahasa Mandarin, perbendaharaan kosa kata dan aksara melalui permainan sederhana, flashcard, kertas lipat, menyanyi lagu-lagu sederhana, cara memperkenalkan diri, dll.

4. Seluruh pihak mitra Yayasan Pendidikan Islam Ar-Rahmah dapat menguasai seluruh materi yang diberikan pada saat pelatihan. Hasil praktek pengajaran yang dilakukan sangat memuaskan dan sesuai dengan yang diharapkan.

5. Tim Pengabdian Kepada Masyarakat USU memberikan apresiasi sangat tinggi kepada seluruh pihak Yayasan Pendidikan Islam ArRahmah sehingga meyumbangkan LCD
Projector sebagai sarana penunjang pembelajaran di yayasan tersebut, khususnya dalam pembelajaran bahasa Mandarin kelak.

\section{SARAN}

Saran yang dapat diberikan oleh Tim Pengabdian Kepada Masyarakat USU terhadap pelatihan yang dilaksanakan, adalah:

1. Kepada seluruh pihak Yayasan Pendidikan Islam Ar-Rahmah hendaknya tetap bersemangat dan antusias jika ada pelatihanpelatihan berikutnya.

2. Kepada seluruh pihak Yayasan Pendidikan Islam Ar-Rahmah hendaknya merealisasikan secepat mungkin niat untuk menjadikan bahasa Mandarin sebagai mata pelajaran di sekolahnya.

3. Kepada seluruh pihak Yayasan Pendidikan Islam Ar-Rahmah agar tetap bersemangat dan sabar mendidik setiap siswa, terkhususnya dalam memberikan pengajaran bahasa Mandarin kelak.

4. Kepada seluruh masyarakat agar dapat mendukung pelatihan yang diberikan oleh Tim Pengabdian Kepada Masyarakat USU kepada mitra/sekolah yang akan diberikanpelatihan Pembelajaran Bahasa Mandarin Anak Usia Dini lainnya.

\section{UCAPAN TERIMA KASIH}

Pengabdian ini dibiayai oleh Non PNBP Universitas Sumatera Utara.Sesuai dengan Surat Perjanjian Penugasan Pelaksanaan Pengabdian kepada Masyarakat Program Mono Tahun Dosen Muda Tahun Anggaran 
2019.Nomor:331/UN5.2.3.2.1/PPM/2019,

Tanggal 20 Mei 2019.

\section{REFERENSI}

[1] Yulianti, Dwi (2010). Bermain Sambil Belajar Sains di Taman Kanak-kanak. Jakarta: PT Indeks

[2] Firdaus, Khodhroul. 2010. Efektivitas Permainan Flashcard dalam Meningkatkan Kemampuan Membaca Anak Prasekolah di TK Sunan Pandan Aran Ngaglik Sleman Yogyakarta. Yogyakarta: Univesitas Islam Negeri Sunan Kali Jaga

[3] Xiaojun, Fan. 2012. Study of Teaching Chinese as a Foreign Language to Children-Take Teaching Chinese to American Children for Example. China: Northeast Normal University

[4] Aisyah, Siti. et.al. 2011. Perkembangan dan Konsep Dasar Pengembangan Anak Usia Dini. Jakarta: Universitas Terbuka

[5] . 2011. Perkembangan dan Konsep Dasar Pengembangan Anak Usia Dini. Jakarta:Universitas Terbuka

[6] Masnipal. 2013. Siap Menjadi Guru dan Pengelola PAUD Profesional.Jakarta: Elex Media Komputindo

[7] Santoso,Soegeng. 2011. Konsep Pendidikan Anak Usia Dini Menurut Pendirinya. Jakarta: Universitas Terbuka 